\title{
Branched chain aldehydes: production and breakdown pathways and relevance for flavour in foods
}

\author{
Bart A. Smit • Wim J.M. Engels • Gerrit Smit
}

Received: 2 September 2008 /Revised: 16 October 2008 / Accepted: 18 October 2008 /Published online: 18 November 2008

(C) The Author(s) 2008. This article is published with open access at Springerlink.com

\begin{abstract}
Branched aldehydes, such as 2-methyl propanal and 2- and 3-methyl butanal, are important flavour compounds in many food products, both fermented and non-fermented (heat-treated) products. The production and degradation of these aldehydes from amino acids is described and reviewed extensively in literature. This paper reviews aspects influencing the formation of these aldehydes at the level of metabolic conversions, microbial and food composition. Special emphasis was on 3-methyl butanal and its presence in various food products. Knowledge gained about the generation pathways of these flavour compounds is essential for being able to control the formation of desired levels of these aldehydes.
\end{abstract}

Keywords Fermentative flavour formation .

Lactic acid bacteria - Amino acid converting enzymes .

Branched chain aldehydes $\cdot 3$-Methylbutanal

\section{B. A. Smit}

Campina Innovation,

Nieuwe Kanaal 7C,

6709PA Wageningen, The Netherlands

W. J. Engels

Department of Flavour, NIZO Food Research,

PO Box 20, 6710 BA Ede, The Netherlands

G. Smit

Department Food Chemistry, Wageningen University,

PO Box 8129, Wageningen, The Netherlands

G. Smit $(\bowtie)$

Department of Flavour Generation and Delivery,

Unilever Food and Health Research Institute,

PO Box 114, 3130 AC Vlaardingen, The Netherlands

e-mail: gerrit.smit@unilever.com

\section{Introduction}

Branched-chain aldehydes, such as 3-methyl butanal, 2methyl butanal and 2-methyl propanal, are potent flavour compounds. In many food products, such aldehydes are key-flavour compounds. Sensorially, they are generally perceived as malty, chocolate-like. An important process leading to the formation of compounds like 3-methyl butanal is the non-enzymic, heat-induced, Strecker degradation of amino groups with reducing sugar moieties (Strecker 1862). Since foods during their production are in many cases subjected to some kind of heat treatment and protein and carbohydrates are generally present, the conditions for the formation of branched-chain aldehydes are favoured. In addition to chemical formation, branchedchain aldehydes are formed during fermentation of many foods. In foods like chocolate/cacao, the combination of fermentation followed by heat treatment gives rise to optimal flavour formation (Counet et al. 2002).

An (branched-chain) aldehyde is an organic compound containing a terminal carbonyl group. This functional group, which consists of a carbon atom bonded to a hydrogen atom and double-bonded to an oxygen atom (chemical formula $\mathrm{O}=\mathrm{CH}-$ ), is called the aldehyde group. The slightly positive carbon atom in the aldehyde group, caused by the electronegative oxygen atom, is susceptible to attacks by nucleophiles, and this makes an aldehyde relatively reactive. Aldehydes can therefore relatively easy be reduced to the corresponding alcohols or oxidised to the corresponding acids. Consequently, aldehydes are generally present only in low concentrations, however, the taste thresholds of aldehydes are also rather low; for 2-methyl propanal and 2- and 3-methyl butanal, they were reported as $0.10,0.13$, and $0.06 \mathrm{mg} / \mathrm{l}$, respectively (Sheldon et al. 1971). 


\section{Formation and conversion}

Although 3-methyl butanal and the other short-chain, branched aldehydes are important flavour compounds in many foods, biochemical conversion routes have been studied mainly in fermented dairy products and chemical conversions mainly in relation to Strecker (Maillard) reactions. This paragraph will focus on influencing the conversion rates leading from and to 3-methyl butanal in several food systems, leaving the biochemical details in the referred papers.

Leucine catabolism

3-Methyl butanal is an intermediate in the catabolism of leucine. A general summary of this catabolism is shown in Fig. 1. The numbers in this figure will be referred to in the next sections and in paragraph headings in parenthesis.

The pathway from leucine via the corresponding $\alpha$-keto acid and aldehyde to alcohol is referred to as the Ehrlich pathway, which was identified in yeasts as the main route for fusel alcohol formation (Ehrlich 1907). In addition to this main route, leucine catabolism may result in hydroxyacids, CoA-esters and other high flavour-impact aldehydes, alcohols and esters. This scheme has extensively been reviewed for lactic acid fermentations (Yvon and Rijnen 2001; Smit et al. 2005b) and alcoholic fermentations (Dickinson 2000b). The catabolism of valine, isoleucine, phenylalanine and methionine proceeds very similarly to the pathway described in this paper for leucine (suggested reviews: Kohlhaw 2003; Fernandez and Zuniga 2006).

Amino acid pool (reactions 1 and 2)

In food systems, leucine is generally liberated from protein by extracellular and intracellular proteolysis (1), although many micro-organisms can also make leucine from threonine (reaction 2). In Lactococcus spp., leucine biosynthesis is encoded by the ILV and LEU operon (Godon et al. 1992, 1993). The last step in the leucine anabolism and first step Leucine catabolism are the same: the conversion between a-keto-isocaproic acid and leucine by a transaminase (Godon et al. 1992). CodY is an important regulator of the internal amino acid pool by controlling peptidase, transporter and transaminase genes, based on isoleucine levels (Chambellon and Yvon 2003). The concentration of isoleucine hereby also affects the concentrations of other amino acids. Proteolysis is essential for liberating enough amino acids for full flavour development. The proteolytic system of micro-organisms is extensively studied and reviewed (Ogrydziak 1993; Fox and McSweeney 1996; Kunji et al. 1996; Christensen et al. 1999; Savijoki et al. 2006). The large variation in peptidase activities among strains of many species may yield a good approach for controlling protein degradation in foods (Ayad et al. 1999; Gatti et al. 2004; Di Cagno et al. 2007; van Hylckama Vlieg and Hugenholtz 2007). In addition to the natural diversity, strains over-expressing peptidases were developed (Van De Guchte et al. 1990; Courtin et al. 2002;
Fig. 1 Metabolic network around 3-methyl butanal

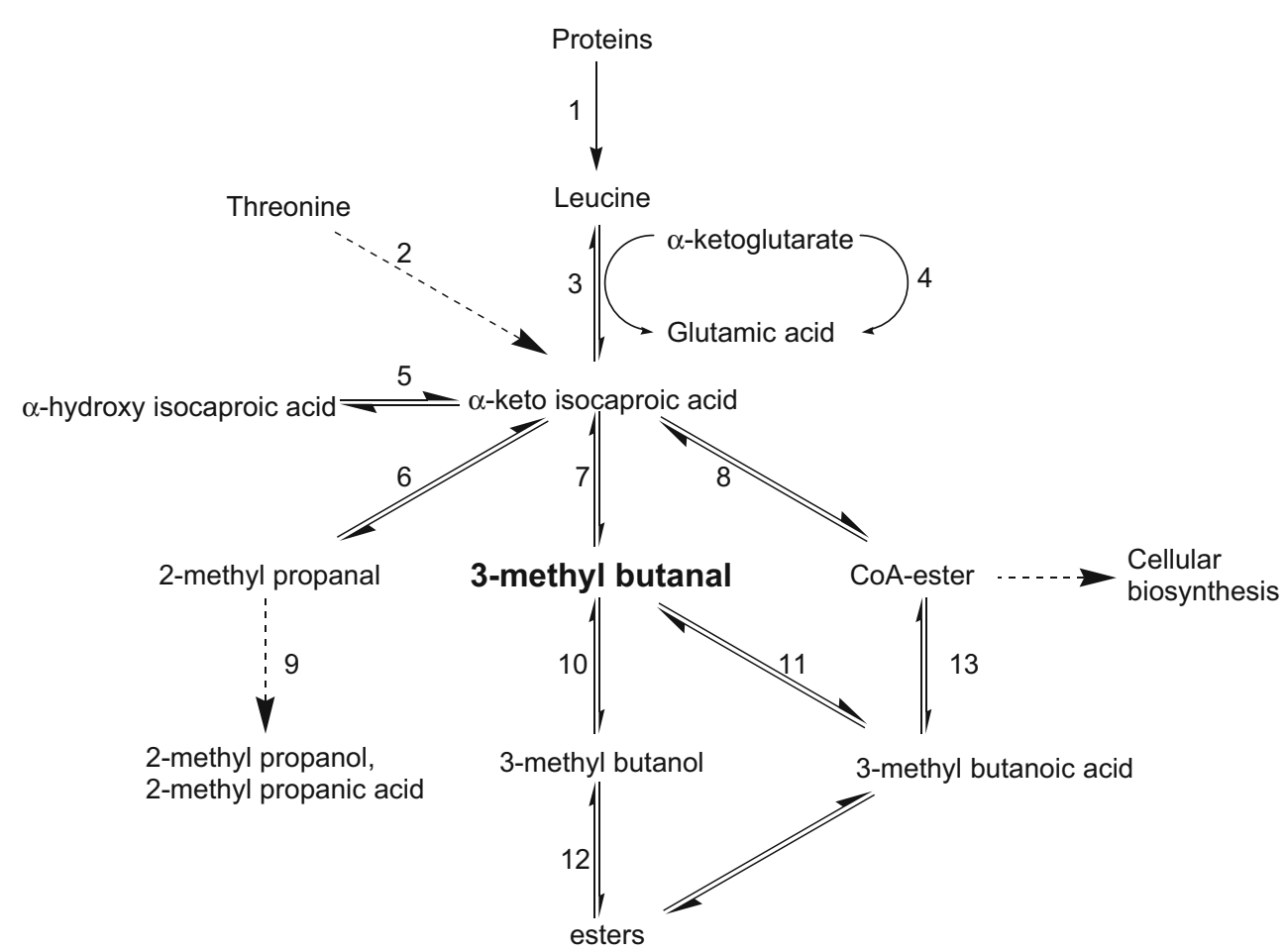


Bockelmann et al. 2006). The increase of amino acids in cheese curd, obtained by the application of peptidase overproducing starter cultures, not only leads to increased flavour perception due to the flavour of the amino acids themselves but also to increased levels of amino acid derived flavour compounds, such as 3-methyl butanal (Exterkate and Alting 1995; Courtin et al. 2002). The same effect was observed in dried sausages (Dura et al. 2004; Herranz et al. 2005; Casaburi et al. 2008) and sourdough (Gänzle et al. 2007).

Transaminase activity (reaction 3)

An initial step in leucine conversion of leucine towards 3methyl butanal is the formation of $\alpha$-keto isocaproic acid. Reaction 3 in Fig. 1 yields this important intermediate and can be catalysed by transaminases and leucine dehydrogenase. In food systems, the transaminases play a major role (Yvon et al. 1997; Engels et al. 2000; Larrouture et al. 2000), while lactic acid bacteria (LAB) related spoilage organisms such as Bacillus spp. and Clostridium spp. possess a leucine dehydrogenase (Zink and Sanwal 1962; Hummel and Kula 1989). Several transaminases have been described, including leucine, branched-chain amino acid, aromatic amino acid and methionine transaminases. These enzymes have overlapping substrate specificities (Gao and Steele 1998; Rijnen et al. 1999a,b; Engels et al. 2000; Yvon et al. 2000; Hansen et al. 2001). Several studies have shown that transaminase presence and activity varies largely among bacterial species and strains (Smit et al. 2004c; Fernandez De Palencia et al. 2006; Liu et al. 2008; van Hylckama Vlieg and Hugenholtz 2007). Knocking out the branched chain amino transferase in Lactococcus lactis resulted in roughly $90 \%$ reduction in leucine transamination (Yvon et al. 2000). The other 10\% conversion was caused by the aspecificity of other transaminases (Engels et al. 2000; Yvon et al. 2000). Knocking out two transaminases in yeast did not lead to a full repression of the fusel alcohol formation because anabolism provided the corresponding $\alpha$-keto acids converted in the Ehrlich pathway (Eden et al. 2001; Schoondermark-Stolk et al. 2005). Knocking out the amino acid anabolism on top of the transaminases still led to minor amounts of 3-methyl butanal and isoamyl alcohol, indicating that an additional pathway or source for $\alpha$-keto isocaproic acid was also present (Eden et al. 2001).

Yvon et al. (1999) were the first to show that adding $\alpha$ keto glutarate to cheese curd leads to increased flavour levels due to increased transamination capacity. Later, this was also shown for other cheese types and for sausages (Larrouture et al. 2000; Banks et al. 2001; Ur-Rehman and Fox 2002; Beck et al. 2004; Herranz et al. 2004; Tjener et al. 2004a; Williams et al. 2004). Instead of adding $\alpha$-ketoglutarate to cheese, the $\alpha$-ketoglutarate can be recycled using the enzyme glutamate dehydrogenase $(\mathrm{GDH}, 4)$. This was shown by introducing a
GDH gene from Peptostreptococcus in a L. lactis strain (Rijnen et al. 2000). Later, the same group showed the presence of this gene in LAB and the natural transfer of the GDH property to starter lactococci (Tanous et al. 2006).

Although increasing amino acid concentrations and enhancing transamination activities were proven to be effective in increasing flavour formation by many food related organisms, only a minor part of the converted leucine accumulates as 3-methyl butanal in food products (Yvon et al. 1999; Kieronczyk et al. 2003; Smit et al. 2004c). This indicates that reaction rates of $\alpha$-keto-isocaproic acid converting enzymes influence the formation of 3-methyl butanal. Several approaches for controlling the competition between various $\alpha$-keto isocaproic acid consuming reactions are described in the following paragraphs.

Branched chain keto acid decarboxylase activity (reaction 7)

This enzyme catalyses the decarboxylation of $\alpha$-keto isocaproic acid to 3-methyl butanal. Its activity in lactococci (Streptococcus lactis) was identified by Tucker and Morgan (1967). In yeast, the presence of such an enzyme besides the specific pyruvate decarboxylase (PDC) was postulated in relation to the production fusel alcohols (Chen 1977; Oku and Kaneda 1988; Ter Schure et al. 1998). Wild lactococcal strains, Corynebacterium (Ayad et al. 1999; Smit et al. 2004c), Carnobacterium (Larrouture et al. 2000), and L. delbreuckii subsp. lactis (Helinck et al. 2004), appeared to posses this activity more generally and with higher activities than LAB used as starter cultures in dairy applications. Smit et al. first discovered the gene encoding the branched chain keto acid decarboxylase enzyme (KdcA) in L. lactis by screening a mutant library of a decarboxylase-positive strain in a decarboxylase-negative strain (Smit 2004). De la Plaza identified a similar enzyme (KivD) by N-terminal sequencing the partially purified protein (De La Plaza et al. 2004). The gene occurs rarely in the sequenced LAB genomes (Liu et al. 2008). In contrast to PDC, KdcA has a very broad substrate specificity, hereby being able to produce various flavour compounds (Smit et al. 2005a; Vuralhan et al. 2005; Yep et al. 2006; Gocke et al. 2007). This broad specificity makes this enzyme also very interesting for use as biocatalyst (Berthold et al. 2007; Gocke et al. 2007). Over-expression of the enzyme was very successful, but in synthetic medium, the 3-methyl butanal production was (only) similar to the wild strain. This indicates that under these conditions, the decarboxylase capacity of the wild strain was not limiting. A test with an over-expression mutant in cheese with or without $\alpha$-ketoglutarate has, to our knowledge, not been described. Food-grade non-starter LAB ("wild-LAB") exhibiting high activity of this enzyme have successfully been applied in cheese (Ayad et al. 2000; Whetstine et al. 2006). 
Hydroxy acid and keto acid dehydrogenases (reactions 5 and 8)

In lactococci, a relatively large amount of leucine is converted in the $\alpha$-hydroxy isocaproic acid (Yvon et al. 1999; Smit et al. 2004c). This is in line with the general desire of converting NADH to $\mathrm{NAD}^{+}$by metabolically active lactic acid bacteria (Schlegel 1997). Over-expression of $\alpha$-hydroxy acid dehydrogenase in Lactobacillus casei followed by applying this strain as adjunct starter in the preparation of cheddar cheese resulted in a decrease of ketoacid derived flavour compounds. This confirms the high impact of this enzyme on the $\alpha$-keto-acid conversion, even when used as adjunct culture (Broadbent et al. 2004; see also below). This implies that knocking out the gene coding for this dehydrogenase in combination with high decarboxylase activity should most probably yield increased flavour levels.

The overall reaction catalysed by the $\alpha$-keto acid dehydrogenase complex is a substitution of $\mathrm{CO}_{2}$ by the cofactor $\mathrm{CoA}$ while reducing $\mathrm{NAD}^{+}$. The enzyme is present and active in yeasts, bacilli, enterococci, propioni bacterium and Lactococcus lactis. The CoA coupled acid can be used in fatty acid biosynthesis or hydrolysed to the branched chain organic acid (reaction 3). This reaction does not lead to the formation of 3-methyl butanal or the corresponding fusel alcohol but produces relatively high amounts of corresponding organic acids, for example by Lactobacillus helveticus (Namba et al. 1969; Derrick and Large 1993; Ward et al. 1999; Dickinson 2000a,b; Hester et al. 2000; Zhu et al. 2005).

\section{Chemical keto-acid conversion (reaction 6)}

Besides various enzymatic conversions, chemical oxidation of $\alpha$-keto-isocaproic acid may occur under cheese-like conditions. This reaction is catalysed by manganese and results in 2-methyl propanal (Smit et al. 2004a). This aldehyde is generally associated with (enzymic) valine catabolism. The activity can be modulated by the $\mathrm{Mn}^{2+}$, oxygen concentration and redox potential (Smit et al. 2004a; Kieronczyk et al. 2006). The variation in the formation of volatiles in a meat model system was mainly determined by $\mathrm{pH}$ and bacterial species and, to a lesser extent, by the manganese concentration (Olesen and Stahnke 2004; Tjener et al. 2004b). This indicates that this chemical conversion is not dominant in this system.

\section{3-Methyl butanal conversion (reactions 10 and 11)}

Once formed, 3-methyl butanal can be converted to compounds such as 3-methyl butanol, 3-methyl butanoic acid, via reduction and oxidation respectively, and esters. In many organisms, 3-methyl butanal is therefore only a transient metabolite (De Vos Petersen et al. 2004). Products from 3-methyl butanal as mentioned clearly add to the (balance in) flavour perception, but their odour threshold is much higher than that of 3-methyl butanal. When maximal flavour is desired, a reduction of these 3-methyl butanal conversions might therefore be beneficial. The natural variation in activity of the enzymes, found in various microbial strains, involved is an appropriate way to control this balance.

Alcohol dehydrogenase (10) catalyses the reduction of 3methyl butanal to 3-methyl butanol. This is the last step in the Ehrlich pathway. This reaction is very active in yeasts (Chen 1977). In many lactic acid bacteria, alcohol dehydrogenase is present, but its activity is much lower (Hatanaka et al. 1974; Schneider-Bernlohr et al. 1981; Bradshaw et al. 1992; Arnau et al. 1998; Temino et al. 2005).

Aldehyde dehydrogenase (11) is also active in many organisms. In Staphylococcus xylosus, it has been shown that 3-methyl butanoic acid is mainly formed by the consecutive decarboxylation of the keto acid followed by oxidation of the aldehyde by a wide spectrum aldehyde dehydrogenase. It has also been shown that the oxidation activity is higher than the decarboxylation activity, resulting in low 3-methyl butanal concentrations (Beck et al. 2002). In yeast, the organic fusel acids can be transported out of the cell by the PDR12p ABC transporter (Hazelwood et al. 2006).

\section{Chemical formation of 3-methyl butanal by Strecker degradation}

The Maillard reaction is very important for the formation of brown colour and flavour in especially heat-treated products such as bread and malt. In short, the Maillard reaction starts with the condensation of an amino group with a reducing sugar leading to a so-called Amadori product. Rearrangement of this Amadori product can lead to dicarbonyls. The reaction of such a dicarbonyl with an amino acid resulting in flavour-active aldehydes is called the Strecker degradation (Strecker 1862; Schonberg and Moubacher 1952). In the case of leucine, deamination followed by decarboxylation results in 3-methyl butanal as shown in Fig. 2 (Pokorny et al. 1973; Baltes 1982; Oberparleiter and Ziegleder 1997; Rizzi 1998). The major control parameters are temperature, but substrate concentrations and substrate characteristics also affect their conversion rates. Already in 1957, Keeny and Day (1957) postulated that this reaction might add to the flavour of cheese, since amino acids and reducing sugars are available in a suitable environment and a long (ripening) time enables the reaction to proceed. Later, several kinetic studies were done with other substrates at elevated temperatures, but no kinetic data under food fermentation conditions (relatively 
Fig. 2 Reaction scheme of the Strecker degradation of leucine (adapted from Rizzi 1998)

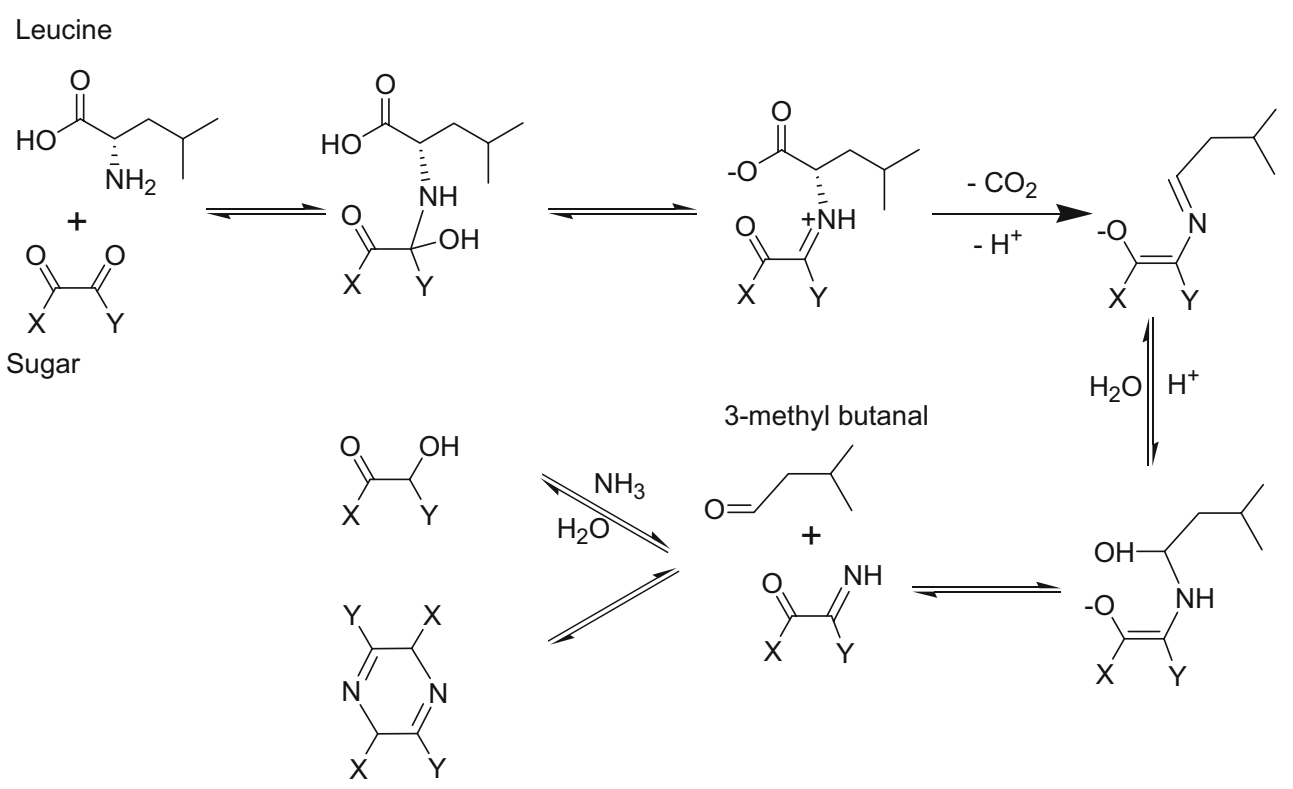

low temperature) have been presented (Hofmann et al. 2000; Martins et al. 2003; Martins and Van Boekel 2005).

\section{Biodiversity, lysis, co-operation}

The intracellular processes, as discussed previously, are influenced by the total food matrix. The chemical and physical properties of the surrounding matrix influence the behaviour of the microbial cell. Other organisms potentially add to the total set of possible reactions in the system. For example, lysis of bacteria is a process where the intracellular enzymes suddenly end up in a total different environment, with not only different substrate and cofactor concentrations but also physical parameters such as $\mathrm{pH}$.

\section{Impact of matrix}

Apart from being present or not, activity of amino acid converting enzymes can also be affected by the growth and culture conditions of the bacteria. This is highly relevant because it also offers opportunities for practical implication. Stress responses to salt and $\mathrm{pH}$ for example stimulate several pathways. In yoghurt, acid pushes the bacterial culture into stationary phase, the phase where most exopolysaccharides and flavours are formed. In cheese, the stationary phase is reached due to a lack of lactose. In this phase, the cofactor pool will change, hereby also affecting the flavour formation. Proteolysis, peptidolysis, transamination and decarboxylation can still proceed, while dehydrogenases will probably be inactive due to a lack of NADH. If this reasoning holds, the main 3-methyl butanal increases should be measurable during carbon-source limited stationary phase.
Extracellular molecules can influence the regulation of several reactions. As stated earlier, isoleucine is able to regulate the amino acid metabolism via CodY (Guedon et al. 2001; Chambellon and Yvon 2003). Adding isoleucine to the cheese matrix should theoretically lead to lower 3-methyl butanal levels by high-3-methyl butanal producing strains.

Besides an impact on regulatory pathways, the previously discussed $\alpha$-ketoglutarate example shows that also changing (limiting) substrate concentrations in the medium can be very effective (Yvon et al. 1999). The addition of amino acids have been described above, but instead of adding free amino acids or peptides, also the addition of proteolytic enzymes has been successfully researched and applied in cheese and sausage productions (Ansorena et al. 2000; Fernandez et al. 2001; Azarnia et al. 2006).

\section{Natural biodiversity}

A large variety in amino acid conversion capacities is found in lactic acid bacteria, particularly among strains isolated from a non-production environment, the so-called wild isolates. Wild strains are often found in environments low in amino acids, which makes them more dependent on their own biosynthesis of amino acids compared to industrial strains, and consequently, they possess more amino acid converting enzymes. In wild lactococci for example, not only a larger enzyme potential is present, but concomitantly also produce rather unusual flavour components and/or flavour profiles (Ayad et al. 1999). This variety is a great source for finding more optimal, more characteristic production organisms. Knowledge on the pathways as described above enables specialized and high-throughput screening of culture collections (Lavery et al. 2001; Smit et al. 2004b; Ingham et al. 2007; van Hylckama Vlieg and 
Hugenholtz 2007; Pastink et al. 2008). The large natural biodiversity could potentially offer specific traits for new products; some examples of using wild starter bacteria in products such as cheese have already been reported (Ayad et al. 2003).

\section{Co-operation between strains}

It is not often that the optimal combination of enzymes can or will be found within one strain. However, in many fermented products, a combination of microbial strains is used, which could potentially result in co-operation of enzymes in a pathway between strains, for instance, upon lysis of the strains (see below). This interaction can be negative, where desired compounds are broken down by another organism, or positive. A combination of strains should be selected, where the total set of conversions is optimal. Screenings, as used for screening the natural biodiversity, are also relevant for the screening of optimal co-operation. For example, Ayad et al. (2001) showed that the combination of two strains, of which each had only a limited set of enzymes in the pathway leading to 3-methyl butanal, were able to complement each other. Kieronczyk et al. $(2003,2004)$ found similar results when combining strains lacking and possessing GDH activities, and Broadbent et al. (2004) showed an example where a Dhydroxyisocaproic acid dehydrogenase over-producing strain could reduce the flavour forming, e.g. 3-methyl butanal, ability of other strains in a mixture. The latter was most likely caused by the effective conversion of keto-acid to non-tasting components (see also above). Genomics approaches offer new opportunities for unravelling and applying microbial co-operation in food fermentations (Sieuwerts et al. 2008).

These examples of co-operation between strains offer new possibilities for the construction of tailor-made starter cultures because it means that not all the required enzyme activities in a certain flavour pathway need to be present in one strain. It was shown that such a co-operation between strains can also work in a real cheese, with again the example of production of 3-methyl butanal as a key compound in that cheese (Ayad et al. 2003; Amarita et al. 2006).

Role of lysis in the formation of branched-chain aldehydes

One could question whether the above-mentioned cooperation can be explained by a diffusion of intermediate compounds in a pathway from one bacterial strain to another or whether this is due to a (partial) lysis of bacteria. In the latter case, the total potential of enzymes would become available as if it was one incubation mixture. The role of cell lysis has extensively been studied with regard to the level of proteolysis and peptidolysis of lactic acid bacteria. Meijer et al. (1998) and Lepeuple et al. (1998) showed that lysis of lactic acid bacteria greatly improved the peptidolytic activity under cheese conditions. Their results indicated that the cell membrane can be a barrier between the enzymes, located intracellularly, and the peptide substrates present in the cheese matrix. Apparently, there is not enough active transport by the starter cultures, for taking up the peptides, once they are present in the cheese matrix, and lysis then is essential for enhancing enzyme-substrate interaction.

In contrast to the activity of peptidases, where lysis generally enhances the activity enzymes, enzymes that require cofactors or cosubstrates (e.g. PLP, NAD, and NADP) could be negatively affected by lysis of the cells. It likely depends on the type of enzyme(system) whether lysis will improve the activity (and formation of flavour) or not. Despite this precaution, it appears from a recent work by various studies that lysis of the bacteria in general seems to increase the formation of flavour components, such as branched-chain aldehydes.

Martinez-Cuesta et al. (2006a,b) reported that cell membrane permeabilisation by lactacins positively influence the formation of aldehydes in lactic acid bacteria. Bourdat-Deschamps et al. (2004) took this further towards cheese models by showing that the conversion of phenylalanine to flavour compounds was enhanced by autolysis. In a study by De Palencia et al. (2004), bacteriocinsensitive strains of $L$. lactis, with BcAA activity and $\alpha$ keto acid decarboxylase activity, were used as adjunct together with a bacteriocin-producing (Lacticin 3147) $L$. lactis strain in cheese making. In control cheese making, a non-bacteriocin producing strain was used. The bacteriocin produced enhanced lysis of the adjunct strains, which led to an increase in isoleucine transamination. The concentration of the flavour compound 2-methylbutanal was about doubled again, indicating that increased aldehyde formation can be obtained due to lysis.

Taken together, lysis appears to improve the conversion rate of intermediates towards branched-chain aldehydes, and this finding may also explain why a combination of strains (with different enzyme activities for the pathway to these aldehydes) can be an effective way to generate branch-chain aldehydes in products like cheese.

\section{Presence and impact of branch-chain aldehydes in various food products}

After having discussed pathways of formation of branchedchain aldehydes and opportunities to influence and control their formation, in this section, we focus on the impact of 3methyl butanal as flavour compound and its formation in 
various important foods. In a large number of foods, 3methyl butanal is a (key) flavour compound, and it is mainly produced by the transaminase-initiated enzymic pathway and by (non-enzymic) Strecker degradation. We will only focus on those products that are subject to a processing step (i.e. heating and fermentation) and not on the presence of these aldehydes in products like tomato or grain, where they can also be detected pre-harvest.

\section{Bread/wheat/sourdough}

Taste and smell are undoubtedly the most important attributes determining the quality of bread or baked cereals in general. 3Methyl butanal, phenylacetaldehyde and 3-(methylthio)propanal are amino-acid-derived key flavour compounds in bread (Schieberle 1996). They are formed essentially in two ways: The enzymatic (Ehrlich) reaction is dominant in the crumb, while the chemical Strecker degradation proceeds fast in the crust during the baking process. Aldehyde concentrations in the crumb generally are low, whereas in the crust, a stronger (Strecker) formation of aldehydes 2- and 3-methyl butanal and 2-methyl propanal is observed during baking (Zehentbauer 2001; Ruiz et al. 2003).

The type of starter cultures used in the fermentation process and the fermentation regime (temperature, time, $\mathrm{pH}$, etc.) differs considerably between several bread types resulting in large differences in 3-methyl butanal levels (Zehentbauer 2001; Ruiz et al. 2003; Gänzle et al. 2007). Sourdough breads are, in addition to bakers yeast, Saccharomyces cerevisiae, produced with lactic acid bacteria (LAB), such as Lactobacillus, Leuconostoc, Pediococcus and Streptococcus. The majority belongs to the genus Lactobacillus, e.g. Lactobacillus sanfrancisco (Hansen and Schieberle 2005). In sourdough breads, these LAB also significantly influence the amounts of 3-methyl butanal and many other odorants, e.g. acetic acid, butanoic acid, phenylacetic acid, 2- and 3-methylbutanoic acid and pentanoic acid (Czerny and Schieberle 2002; Gänzle et al. 2007; Van Der Meulen et al. 2007). 3-Methyl butanal concentration in the flour is low, and LAB may increase the concentration by a factor of 4. In addition, yeast fermentation yields 3-methyl butanal. The results of research on sourdough breads suggested that, in some cases, no free leucine was left over after fermentation, thereby indicating the need to form sufficient amounts of the free amino acids during fermentation (Czerny and Grosch 2000; Hansen et al. 2001; Kirchhoff and Schieberle 2002; Hansen and Schieberle 2005; Corsetti and Settanni 2007; Corsetti et al. 2007).

Zehentbauer and Grosch (Zehentbauer 2001) observed, in addition to differences in formation of Strecker aldehydes depending on the ingredients and recipe used for bread making, also differences in losses of 2-methyl propanal, 2and 3-methyl butanal. It can be assumed that the formation and losses of both desired and undesired compounds (leading to off-flavour) determine overall flavour balance (Zehentbauer 2001; Czerny and Schieberle 2002).

In rice cakes, produced without fermentation, various volatile flavour compounds were formed in the whole product due to the baking process, including aldehydes 2- and 3methyl butanal (Buttery et al. 1999).

\section{Chocolate/cocoa}

The secret of the flavour of chocolate resides mainly in its volatile aromatic fraction. At least 35 key aroma compounds could be identified in chocolate (Counet et al. 2002; Frauendorfer and Schieberle 2006). Three of those compounds had a strong chocolate-like flavor: 2-methylpropanal, 2-methylbutanal and 3-methyl butanal. Many others were characterized by cocoa/praline-flavoured/nutty/coffee notes, e.g. pyrazines (Counet et al. 2002).

The first processing step of cocoa beans involves fermentation with $\mathrm{LAB}$, acetic acid bacteria and yeasts (Nielsen et al. 2007). This cocoa fermentation is crucial not only to the formation of significant volatile fractions (alcohols, esters and fatty acids) but also for the development of cocoa-chocolate flavor precursors (amino acids and reducing sugars). Cocoa is dried to minimize the formation of moulds and to reduce the acid level and astringency of the beans by decreasing the total quantity of polyphenols. Via Maillard reactions, subsequent cocoa roasting converts flavor precursors formed during fermentation to two main classes of odorant compounds already mentioned: pyrazines and aldehydes (Kattenberg and Kemming 1993). Concentrations between 20 and $60 \mathrm{mg} / \mathrm{kg}$ have been found for 3-methyl butanal (Ziegleder 1991).

\section{Meat}

For storage and preservation purposes, meat is treated in various ways, of which some have a strong impact on flavour. Examples are fermentation and drying. These processes may yield significant levels of 3-methyl butanal. Two types of starter culture, lactic acid bacteria and Micrococcaceae, are often used in combination when producing fermented sausages. Lactic acid bacteria, e.g. Lactobacillus sakei and Pediococcus pentosaceus, cause a lowering of the $\mathrm{pH}$, thereby preventing growth of many pathogenic microorganisms. The Micrococcaceae, e.g. S. xylosus and Staphylococcus carnosus, are added due to their nitrate and nitrite reductase activity, which assists in color formation (Lucke 1998; De Vos Petersen et al. 2004). Furthermore, the Micrococcaceae also produce pleasant flavors, such as those associated with the branched-chain aldehydes contributing significantly to odor perception of the final product (Montel et al. 1996). 
The microbial catabolism of leucine by LAB and Staphylococcus species and by, e.g. Carnobacterium species and Moraxella has been studied by various groups (Montel et al. 1996; Stahnke 1999a,b; Marco et al. 2007). Masson et al. demonstrated catabolism of leucine by $S$. carnosus yielding 3-methyl butanal, 3-methyl butanol and 3-methyl butanoic acid (Masson et al. 1999). It appeared that the preculture and incubation conditions strongly influenced the level of production of the three metabolites. The reactions yielding 3-methyl butanal were those already described for $\mathrm{LAB}$ in the previous section (Fig. 1). Oxidation of 3-methyl butanal then might yield 3-methyl butanoic acid. In addition, direct oxidative decarboxylation yielding 3-methyl butanoic acid from the keto acid was suggested (Masson et al. 1999). Carnobacterium piscicola is also able to form 3-methyl butanal and 3-methyl butanol via $\alpha$-ketoisocaproic acid (Larrouture-Thiveyrat and Montel 2003; Larrouture-Thiveyrat et al. 2003). Moraxella phenylpuruvica degraded both leucine and phenylalanine yielding 3-methyl butanal and benzaldehyde/benzacetaldehyde (Møller et al. 1998).

In dry-cured ham, 2- and 3-methyl butanal have been associated with nutty, cheese and salty notes, e.g. in Parma ham (Andres et al. 2002), Iberian ham (Andres et al. 2005) and American country ham (Song et al. 2008). The formation is probably non-enzymic via Strecker reaction, since no fermentation takes place in the product. This is a slow process, at temperatures applied during dry-cured ham ripening, but long ripening times may facilitate this reaction (Andres et al. 2002).

\section{Soy fermentations}

Soy sauce is traditionally used as seasoning in eastern Asia, and its popularity in the Western part of the world is growing due to its intense umami taste accompanied by a very characteristic aroma (Steinhaus and Schieberle 2007). Japanese soy sauce (shoyu) is traditionally produced by fermentation of heated soybeans and wheat flour with Aspergillus oryzae or Aspergillus sojae to koji. In the next step, the koji is fermented with Pediococcus halophilus and Zygosaccharomyces rouxii to yield moromi. Pressing of moromi then yields the soy sauce, which is finally pasteurized and bottled. For the aroma development of Japanese soy sauce, all these steps are important. For Chinese soy sauce, only soybeans but no cereals are used, whereas Korean soy sauce is produced from soybeans, barley meal, and various spices (Nunomura and Sasaki 1992). 3-Methyl butanal and 2-methyl butanal are amongst the most important odorants in soy sauce and are thought to be essentially produced by microbial action via both the Ehrlich pathway and via amino-acid biosynthetic pathways of branched-chain amino acids leucine, valine and isoleu- cine. In addition to the aldehydes, the oxidation and reduction products such as 3-methylbutanoic acid and (fusel) alcohols are regarded as key aroma compounds (van der Sluis et al. 2000, 2002; Steinhaus and Schieberle 2007).

\section{Beverages}

In beverages such as (fermented) black tea and coffee, 3methyl butanal is thought to be a key contributor to aroma (Czerny and Grosch 2000; Kumazawa and Masuda 2001; Wright et al. 2007). In wine, branched-chain alcohols, e.g. isoamyl alcohol and isobutanol, are synthesised in the yeast cell through the Ehrlich pathway by degradation of branched-chain amino acids (Ehrlich 1907). Mitochondrial and cytosolic enzymes of $S$. cerevisiae are involved in the initial $\alpha$-keto acid formation from the amino acids. A decarboxylase converts the resulting $\alpha$-keto acid to the corresponding branched-chain aldehyde, e.g. 3-methyl butanal, with one carbon-less atom, and the alcohol dehydrogenase catalyses the NADH-dependent reduction of this aldehyde to the corresponding fusel alcohol. Alternatively, the aldehyde might be oxidised to a carbolic acid (Derrick and Large 1993; Dickinson and Norte 1993; Didion et al. 1996; Swiegers et al. 2005; Swiegers and Pretorius 2005).

Although the branched-chain aldehydes are generally not regarded as key flavour compounds in wine, in some wine or wine products, 3-methyl butanal definitely contributes to flavour, e.g. in Pedro Ximenez, Fino, botrytized Sauternes and Cava wines that contain relatively high concentrations of this aldehyde (Campo et al. 2008). Sherry wines and Port may also have large amounts of branched aldehydes (Cullere et al. 2007). Potential key aroma compounds of freshly distilled Calvados and Cognac were 3-methyl butanal and hexanal (Ledauphin et al. 2006a, b).

Beer is made by fermenting a malt extract with $S$. cerevisiae. Malt is predominantly produced by germinating barley followed by a drying process called kilning (Fickert and Schieberle 1998). 3-Methyl and 2-methyl butanal were determined as the most odor-active compounds in malt (Zhou et al. 2002; Cramer et al. 2005). Nevertheless, aldehyde levels in beer are usually low and increase over shelf life. In aged beer, 2-methyl propanal, 2-methyl butanal, 3-methyl butanal, pentanal, hexanal, furfural, methional, phenylacetaldehyde, and (E)-2-nonenal can be detected and are in some cases undesired (Vesely et al. 2003; Vanderhaegen et al. 2007).

\section{Concluding remark}

Branched aldehydes, such as 3-methyl butanal, are important flavour compounds in many food products, both 
fermented and non-fermented (heat-treated) products. Knowledge gained about the generation pathways of these flavour compounds is essential for being able to control the formation of desired levels of these aldehydes. Currently, good examples of these are already implemented in fermented food products such as cheese, and there is a great potential to also implement this in other fermented and non-fermented food products.

Open Access This article is distributed under the terms of the Creative Commons Attribution Noncommercial License which permits any noncommercial use, distribution, and reproduction in any medium, provided the original author(s) and source are credited.

\section{References}

Amarita F, De La Plaza M et al (2006) Cooperation between wild lactococcal strains for cheese aroma formation. Food Chem 94 (2):240-246

Andres AI, Cava R et al (2002) Monitoring volatile compounds during dry-cured ham ripening by solid-phase microextraction coupled to a new direct-extraction device. J Chromatogr A 963(1-2):83-88

Andres AI, Ventanas S et al (2005) Physicochemical changes throughout the ripening of dry cured hams with different salt content and processing conditions. Eur Food Res Technol 221(1-2):30-35

Ansorena D, Astiasaran I et al (2000) Influence of the simultaneous addition of the protease flavourzyme and the lipase Novozym 677BG on dry fermented sausage compounds extracted by SDE and analyzed by GC-MS. J Agric Food Chem 48(6):2395-2400

Arnau J, Jørgensen F et al (1998) Cloning of the Lactococcus lactis adhE gene, encoding a multifunctional alcohol dehydrogenase, by complementation of a fermentative mutant of Escherichia coli. J Bacteriol 180(12):3049-3055

Ayad EHE, Verheul A et al (1999) Flavour forming abilities and amino acid requirements of Lactococcus lactis strains isolated from artisanal and non-dairy origin. Int Dairy J 9(10):725-735

Ayad EHE, Verheul A et al (2000) Application of wild starter cultures for flavour development in pilot plant cheese making. Int Dairy J 10(3):169-179

Ayad EHE, Verheul A et al (2001) Enhanced flavour formation by combination of selected lactococci from industrial and artisanal origin with focus on completion of a metabolic pathway. J Appl Microbiol 90(1):59-67

Ayad EHE, Verheul A et al (2003) Starter culture development for improving the flavour of Proosdij-type cheese. Int Dairy J 13(23):159-168

Azarnia S, Robert $\mathrm{N}$ et al (2006) Biotechnological methods to accelerate cheddar cheese ripening. Crit Rev Biotechnol 26 (3): 121-143

Baltes W (1982) Chemical changes in food by the Maillard reaction. Food Chem 9(1-2):59-73

Banks JM, Yvon M et al (2001) Enhancement of amino acid catabolism in cheddar cheese using alpha-ketoglutarate: amino acid degradation in relation to volatile compounds and aroma character. Int Dairy J 11(4-7):235-243

Beck HC, Hansen AM et al (2002) Metabolite production and kinetics of branched-chain aldehyde oxidation in Staphylococcus xylosus. Enzyme Microbial Technol 31(1-2):94-101

Beck HC, Hansen AM et al (2004) Catabolism of leucine to branchedchain fatty acids in Staphylococcus xylosus. J Appl Microbiol 96 (5):1185-1193
Berthold CL, Gocke D et al (2007) Structure of the branched-chain keto acid decarboxylase (KdcA) from Lactococcus lactis provides insights into the structural basis for the chemoselective and enantioselective carboligation reaction. Acta Crystallogr D Biol Crystallogr 63(12):1217-1224

Bockelmann W, Golecki S et al (2006) Cheese ripening with Lactococcus lactis starters containing additional peptidase genes from Lactobacillus delbrueckii subsp. lactis. Kiel Milchwirtsch Forschungsber 58(2):93-107

Bourdat-Deschamps M, Le Bars D et al (2004) Autolysis of Lactococcus lactis AM2 stimulates the formation of certain aroma compounds from amino acids in a cheese model. Int Dairy J 14(9):791-800

Bradshaw CW, Hummel W et al (1992) Lactobacillus kefir alcohol dehydrogenase: a useful catalyst for synthesis. J Org Chem 57 (5): $1532-1536$

Broadbent JR, Gummalla S et al (2004) Overexpression of Lactobacillus casei D-hydroxyisocaproic acid dehydrogenase in cheddar cheese. Appl Environ Microbiol 70(8):4814-4820

Buttery RG, Orts WJ et al (1999) Volatile flavor components of rice cakes. J Agric Food Chem 47(10):4353-4356

Campo E, Cacho J et al (2008) The chemical characterization of the aroma of dessert and sparkling white wines (Pedro Ximenez, Fino, Sauternes, and Cava) by gas chromatography-olfactometry and chemical quantitative analysis. J Agric Food Chem 56(7):2477-2484

Casaburi A, Di Monaco R et al (2008) Proteolytic and lipolytic starter cultures and their effect on traditional fermented sausages ripening and sensory traits. Food Microbiol 25(2):335-347

Chambellon E, Yvon M (2003) CodY-regulated aminotransferases AraT and BcaT play a major role in the growth of Lactococcus lactis in milk by regulating the intracellular pool of amino acids. Appl Environ Microbiol 69(6):3061-3068

Chen ECH (1977) Keto acid decarboxylase and alcohol dehydrogenase activities of yeast in relation to the formation of fusel alcohols. Can Inst Food Sci Techn 10(1):27-30

Christensen JE, Dudley EG et al (1999) Peptidases and amino acid catabolism in lactic acid bacteria. Antonie van Leeuwenhoek 76 $(1-4): 217-246$

Corsetti A, Settanni L (2007) Lactobacilli in sourdough fermentation. Food Res Int 40(5):539-558

Corsetti A, Settanni L et al (2007) Identification of subdominant sourdough lactic acid bacteria and their evolution during laboratory-scale fermentations. Food Microbiol 24(6):592-600

Counet C, Callemien D et al (2002) Use of gas chromatographyolfactometry to identify key odorant compounds in dark chocolate. Comparison of samples before and after conching. J Agric Food Chem 50(8):2385-2391

Courtin P, Nardi M et al (2002) Accelerating cheese proteolysis by enriching Lactococcus lactis proteolytic system with lactobacilli peptidases. Int Dairy J 12(5):447-454

Cramer A-CJ, Mattinson DS et al (2005) Analysis of volatile compounds from various types of barley cultivars. J Agric Food Chem 53(19):7526-7531

Cullere L, Cacho J et al (2007) An assessment of the role played by some oxidation-related aldehydes in wine aroma. J Agric Food Chem 55(3):876-881

Czerny M, Grosch W (2000) Potent odorants of raw Arabica coffee. Their changes during roasting. J Agric Food Chem 48(3):868-872

Czerny M, Schieberle P (2002) Important aroma compounds in freshly ground wholemeal and white wheat flour - Identification and quantitative changes during sourdough fermentation. J Agric Food Chem 50(23):6835-6840

De La Plaza M, De Palencia PF et al (2004) Biochemical and molecular characterization of a-ketoisovalerate decarboxylase, an enzyme involved in the formation of aldehydes from amino acids by Lactococcus lactis. FEMS Microbiol Lett 238(2):367-374 
De Palencia PF, De La Plaza M et al (2004) Enhancement of 2methylbutanal formation in cheese by using a fluorescently tagged Lacticin 3147 producing Lactococcus lactis strain. Int J Food Microbiol 93(3):335-347

De Vos Petersen C, Beck HC et al (2004) On-line monitoring of important organoleptic methyl-branched aldehydes during batch fermentation of starter culture Staphylococcus xylosus reveal new insight into their production in a model fermentation. Biotechnol Bioeng 85(3):298-305

Derrick S, Large PJ (1993) Activities of the enzymes of the Ehrlich pathway and formation of branched-chain alcohols in Saccharomyces cerevisiae and Candida utilis grown in continuous culture on valine or ammonium as sole nitrogen source. J Gen Microbiol 139(11):2783-2792

Di Cagno R, De Angelis M et al (2007) Genotypic and phenotypic diversity of Lactobacillus rossiae strains isolated from sourdough. J Appl Microbiol 103(4):821-835

Dickinson JR (2000a) Branched-chain keto acid dehydrogenase of yeast. Methods Enzymol 324:389-398

Dickinson JR (2000b) Pathways of leucine and valine catabolism in yeast. Methods Enzymol 324:80-94

Dickinson JR, Norte V (1993) A study of branched-chain amino acid aminotransferase and isolation of mutations affecting the catabolism of branched-chain amino acids in Saccharomyces cerevisiae. FEBS Lett 326(1-3):29-32

Didion T, Grauslund M et al (1996) Amino acids induce expression of BAP2, a branched-chain amino acid permease gene in Saccharomyces cerevisiae. J Bacteriol 178(7):2025-2029

Dura MA, Flores M et al (2004) Effect of Debaryomyces spp. on the proteolysis of dry-fermented sausages. Meat Sci 68(2):319-328

Eden A, Van Nedervelde L et al (2001) Involvement of branchedchain amino acid aminotransferases in the production of fusel alcohols during fermentation in yeast. Appl Microbiol Biotechnol 55(3):296-300

Ehrlich F (1907) Über die Bedingungen der Fuselölbindungen und über ihnen Zusammenhang mit dem Eiweissaufbau der Hefe. Ber Dtsch Chem Ges 40:1027-1047

Engels WJM, Alting AC et al (2000) Partial purification and characterization of two aminotransferases from Lactococcus lactis subsp. cremoris B78 involved in the catabolism of methionine and branched-chain amino acids. Int Dairy J 10(7):443-452

Exterkate FA, Alting AC (1995) The role of starter peptidases in the initial proteolytic events leading to amino acids in Gouda cheese. Int Dairy J 5(1):15-28

Fernandez M, Zuniga M (2006) Amino acid catabolic pathways of lactic acid bacteria. Crit Rev Microbiol 32(3):155-183

Fernandez M, Ordoez JA et al (2001) Accelerated ripening of dry fermented sausages. Trends Food Sci Technol 11(6):201-209

Fernandez De Palencia P, De La Plaza M et al (2006) Diversity of amino acid converting enzymes in wild lactic acid bacteria. Enzyme Microbial Technol 38(1-2):88-93

Fickert B, Schieberle P (1998) Identification of the key odorants in barley malt (caramalt) using GC/MS techniques and odour dilution analyses. Die Nahrung 42(6):371-375

Fox PF, McSweeney PL (1996) Proteolysis in cheese during ripening. Food Rev Int 12(4):457-509

Frauendorfer F, Schieberle P (2006) Identification of the key aroma compounds in cocoa powder based on molecular sensory correlations. J Agric Food Chem 54(15):5521-5529

Gänzle MG, Vermeulen N et al (2007) Carbohydrate, peptide and lipid metabolism of lactic acid bacteria in sourdough. Food Microbiol 24(2):128-138

Gao S, Steele JL (1998) Purificartion and characterization of oligomeric species of an aromatic amino acid aminotransferase from Lactococcus lactis subsp lactis S3. J Food Biochem 22:197-211
Gatti M, Fornasari ME et al (2004) Peptidase activity in various species of dairy thermophilic lactobacilli. J Appl Microbiol 96 (2):223-229

Gocke D, Nguyen CL et al (2007) Branched-chain keto acid decarboxylase from Lactococcus lactis (KdcA), a valuable thiamine diphosphate-dependent enzyme for asymmetric $\mathrm{C}-\mathrm{C}$ bond formation. Adv Synth Catal 349(8-9):1425-1435

Godon J-J, Chopin M-C et al (1992) Branched-chain amino acid biosynthesis genes in Lactococcus lactis subsp. lactis. J Bacteriol 174(20):6580-6589

Godon J-J, Delorme C et al (1993) Gene inactivation in Lactococcus lactis: Branched-chain amino acid biosynthesis. J Bacteriol 175 (14):4383-4390

Guedon E, Serror P et al (2001) Pleiotropic transcriptional repressor CodY senses the intracellular pool of branched-chain amino acids in Lactococcus lactis. Mol Microbiol 40(5):1227-1239

Hansen A, Schieberle P (2005) Generation of aroma compounds during sourdough fermentation: applied and fundamental aspects. Trends Food Sci Technol 16(1-3):85-94

Hansen BV, Houlberg U et al (2001) Transamination of branchedchain amino acids by a cheese related Lactobacillus paracase strain. Int Dairy J 11(4-7):225-233

Hatanaka A, Kajiwara T et al (1974) Purification and properties of alcohol dehydrogenase from Leuconostoc mesenteroides. Agric Biol Chem 38(10):1819-1833

Hazelwood LA, Tai SL et al (2006) A new physiological role for Pdr12p in Saccharomyces cerevisiae: Export of aromatic and branched-chain organic acids produced in amino acid catabolism. FEMS Yeast Res 6(6):937-945

Helinck S, Le Bars D et al (2004) Ability of thermophilic lactic acid bacteria to produce aroma compounds from amino acids. Appl Environ Microbiol 70(7):3855-3861

Herranz B, Fernandez M et al (2004) Use of Lactococcus lactis subsp. cremoris NCDO 763 and a-ketoglutarate to improve the sensory quality of dry fermented sausages. Meat Sci 66(1):151-163

Herranz B, De La Hoz L et al (2005) Improvement of the sensory properties of dry-fermented sausages by the addition of free amino acids. Food Chem 91(4):673-682

Hester KL, Luo J et al (2000) Purification of Pseudomonas putida branched-chain keto acid dehydrogenase E1 component. Methods Enzymol 324:129-138

Hofmann T, Muench P et al (2000) Quantitative model studies on the formation of aroma-active aldehydes and acids by strecker-type reactions. J Agric Food Chem 48(2):434-440

Hummel W, Kula M-R (1989) Dehydrogenases for the synthesis of chiral compounds. Eur J Biochem 184(1):1-13

Ingham CJ, Sprenkels A et al (2007) The micro-Petri dish, a millionwell growth chip for the culture and high-throughput screening of microorganisms. Proc Natl Acad Sci U S A 104(46):18217-18222

Kattenberg H, Kemming A (1993) The flavor of cocoa in relation to the origin and processing of the cocoa beans. In: Charalambous G (ed) Food flavours, ingredients and composition. Elsevier Science, Amsterdam, The Netherlands, pp 1-22

Keeney M, Day EA (1957) Probable role of the strecker degradation of amino acids in development of cheese flavor. J Dairy Sci 40 (7):874-876

Kieronczyk A, Skeie S et al (2003) Cooperation between Lactococcus lactis and nonstarter lactobacilli in the formation of cheese aroma from amino acids. Appl Environ Microbiol 69(2):734-739

Kieronczyk A, Skeie S et al (2004) The nature of aroma compounds produced in a cheese model by glutamate dehydrogenase positive Lactobacillus INF15D depends on its relative aminotransferase activities towards the different amino acids. Int Dairy J 14 (3):227-235

Kieronczyk A, Cachon R et al (2006) Addition of oxidizing or reducing agents to the reaction medium influences amino acid 
conversion to aroma compounds by Lactococcus lactis. J Appl Microbiol 101(5):1114-1122

Kirchhoff E, Schieberle P (2002) Quantitation of odor-active compounds in rye flour and rye sourdough using stable isotope dilution assays. J Agric Food Chem 50(19):5378-5385

Kohlhaw GB (2003) Leucine biosynthesis in fungi: entering metabolism through the back door. Microbiol Mol Biol Rev 67(1):1-15

Kumazawa K, Masuda H (2001) Change in the flavor of black tea drink during heat processing. J Agric Food Chem 49(7):3304-3309

Kunji ERS, Mierau I et al (1996) The proteolytic systems of lactic acid bacteria. Ant Leeuwenhoek 70:187-221

Larrouture C, Ardaillon V et al (2000) Ability of meat starter cultures to catabolize leucine and evaluation of the degradation products by using an HPLC method. Food Microbiol 17(5):563-570

Larrouture-Thiveyrat C, Montel M-C (2003) Effects of environmental factors on leucine catabolism by Carnobacterium piscicola. Int $\mathrm{J}$ Food Microbiol 81(3):177-184

Larrouture-Thiveyrat C, Pepin M et al (2003) Effect of Carnobacterium piscicola on aroma formation in sausage mince. Meat Sci 63(3):423-426

Lavery P, Brown MJB et al (2001) Simple absorbance-based assays for ultra-high througput screening. J Biomol Scr 6(1):3-9

Ledauphin J, Barillier D et al (2006a) Gas chromatographic quantification of aliphatic aldehydes in freshly distilled Calvados and Cognac using 3-methylbenzothiazolin-2-one hydrazone as derivative agent. J Chrom A 1115(1-2):225-232

Ledauphin J, Basset B et al (2006b) Identification of trace volatile compounds in freshly distilled Calvados and Cognac: carbonyl and sulphur compounds. J Food Compos Anal 19(1):28-40

Lepeuple A-S, Vassal L et al (1998) Involvement of a prophage in the lysis of Lactococcus lactis subsp. cremoris AM2 during cheese ripening. Int Dairy J 8(7):667-674

Liu M, Siezen R (2006) Comparative genomics of flavour-forming pathways in lactic acid bacteria. Aust J Dairy Technol 61(2):61-68

Liu M, Nauta A et al (2008) Comparative genomics of enzymes in flavor-forming pathways from amino acids in lactic acid bacteria. Appl Environ Microbiol 74(15):4590-4600

Lucke FK (1998) Fermented sausages. In: Wood BJB (ed) Microbiology of fermented foods, 2nd edn. Blackie Academic and Professional, London

Marco A, Navarro JL et al (2007) Quantitation of selected odor-active constituents in dry fermented sausages prepared with different curing salts. J Agric Food Chem 55(8):3058-3065

Martinez-Cuesta MC, Requena T et al (2006a) Permeabilization and lysis induced by bacteriocins and its effect on aldehyde formation by Lactococcus lactis. Biotechnol Lett 28(19):1573-1580

Martinez-Cuesta MC, Requena T et al (2006b) Cell membrane damage induced by lacticin 3147 enhances aldehyde formation in Lactococcus lactis IFPL730. Int J Food Microbiol 109(3):198-204

Martins SIFS, Van Boekel MAJS (2005) Kinetics of the glucose/ glycine Maillard reaction pathways: influences of $\mathrm{pH}$ and reactant initial concentrations. Food Chem 92(3):437-448

Martins SIFS, Marcelis ATM et al (2003) Kinetic modelling of Amadori $\mathrm{N}$-(1-deoxy-D-fructos-1-yl)-glycine degradation pathways. Part IReaction mechanism. Carbohydr Res 338(16):1651-1663

Masson F, Hinrichsen L et al (1999) Factors influencing luecine catabolism by a strain of Staphylococcus carnosus. Int J Food Microbiol 49:173-178

Meijer W, van de Bunt B et al (1998) Lysis of Lactococcus lactis subsp. lactis SK110 and its nisin-immune transconjugant in relation to flavor development in cheese. Appl Environ Microbiol 64(5):1950-1953

Møller JKS, Hinrichsen LL et al (1998) Formation of amino acid (Lleucine, L-phenylalanine) derived volatile flavour compounds by Moraxella phenylpyruvica and Staphylococcus xylosus in cured meat model systems. Int J Food Microbiol 42(1-2):101-117
Montel M-C, Reitz J et al (1996) Biochemical activities of Micrococcaceae and their effects on the aromatic profiles and odours of a dry sausage model. Food Microbiol 13(6):489-499

Namba Y, Yoshizawa K et al (1969) Coenzyme A- and nicotinamide adenine dinucleotide-sdependent branched chain a-keto acid dehydrogenase. J Biol Chem 244(16):4437-4447

Nielsen DS, Teniola OD et al (2007) The microbiology of Ghanaian cocoa fermentations analysed using culture-dependent and cultureindependent methods. Int J Food Microbiol 114(2):168-186

Nunomura N, Sasaki M (1992) Japanese soy sauce flavor with emphasis on off-flavors. Dev Food Sci 28:287-312

Oberparleiter S, Ziegleder G (1997) Amadori-compounds as cocoa aroma precursors [Amadori-Verbindungen als Aromavorstufen in Kakao]. Nahrung 41(3):142-145

Ogrydziak DM (1993) Yeast extracellular proteases. Crit Rev Biotechnol 13(1):1-55

Oku H, Kaneda T (1988) Biosynthesis of branched-chain fatty acids in Bacillus subtilis. A decarboxylase is essential for branched-chain fatty acid synthetase. J Biol Chem 263(34):18386-18396

Olesen PT, Stahnke LH (2004) The influence of environmental parameters on the catabolism of branched-chain amino acids by Staphylococcus xylosus and Staphylococcus carnosus. Food Microbiol 21(1):43-50

Pastink MI, Sieuwerts S et al (2008) Genomics and high-throughput screening approaches for optimal flavour production in dairy fermentation. Int Dairy J 18(8):781-789

Pokorny J, Luan N-T et al (1973) Non-enzymic browning-VII. Reactions of some tocopherol oxidation products with protein. $\mathrm{Z}$ Lebensm Unters Forsch 152(2):65-70

Rijnen L, Bonneau S et al (1999a) Genetic characterization of the major lactococcal aromatic aminotransferase and its involvement in conversion of amino acids to aroma compounds. Appl Environ Microbiol 65(11):4873-4880

Rijnen L, Delacroix Buchet A et al (1999b) Inactivation of lactococcal aromatic aminotransferase prevents the formation of floral aroma compounds from aromatic amino acids in semi-hard cheese. Int Dairy J 9(12):877-885

Rijnen L, Courtin P et al (2000) Expression of a heterologous glutamate dehydrogenase gene in Lactococcus lactis highly improves the conversion of amino acids to aroma compounds. Appl Environ Microbiol 66(4):1354-1359

Rizzi GP (1998) The Strecker degradation and its contribution to food flavour. In: Teranishi R, Wick EL, Hornstein I (eds) Flavor chemistry: 30 years of progress. Kluwer, Dortrecht, pp 335-345

Ruiz JA, Quilez J et al (2003) Solid-phase microextraction method for headspace analysis of volatile compounds in bread crumb. Cereal Chem 80(3):255-259

Savijoki K, Ingmer H et al (2006) Proteolytic systems of lactic acid bacteria. Appl Microbiol Biotechnol 71(4):394-406

Schieberle P (1996) Odour-active compounds in moderately roasted sesame. Food Chem 55(2):145-152

Schlegel HG (1997) Lactic acid fermentation and lactobacteriaceae. In: Kogut M (ed) General microbiology. Cambridge University Press, Cambridge, pp 300-308

Schneider-Bernlohr H, Fiedler H et al (1981) Alcohol dehydrogenase from Leuconostoc mesenteroides: molecular properties in comparison with the yeast and horse liver enzyme. Int J Biochem 13 (12): $1215-1224$

Schonberg A, Moubacher R (1952) The Strecker degradation of aamino acids. Chem Rev 50(2):261-277

Schoondermark-Stolk SA, Tabernero M et al (2005) Bat2p is essential in Saccharomyces cerevisiae for fusel alcohol production on the nonfermentable carbon source ethanol. FEMS Yeast Res 5(8):757-766

Sheldon RM, Lindsay RC et al (1971) Chemical nature of malty flavor and aroma produced by Streptococcus lactis var. maltigenes. Appl Microbiol 22(3):263-266 
Sieuwerts S, de Bok FAM et al (2008) Unraveling microbial interactions in food fermentations: from classical to genomics approaches. Appl Environ Microbiol 74(16):4997-5007

Smit BA (2004) Formation of amino acid derived cheese flavour compounds. PhD Thesis Wageningen University, Wageningen, The Netherlands

Smit BA, Engels WJ et al (2004a) Chemical conversion of alpha-keto acids in relation to flavor formation in fermented foods. J Agric Food Chem 52(5):1263-1268

Smit BA, Engels WJ et al (2004b) Development of a high throughput screening method to test flavour-forming capabilities of anaerobic micro-organisms. J Appl Microbiol 97(2):306-313

Smit BA, Engels WJ et al (2004c) Diversity of L-leucine catabolism in various microorganisms involved in dairy fermentations, and identification of the rate-controlling step in the formation of the potent flavour component 3-methylbutanal. Appl Microbiol Biotechnol 64(3):396-402

Smit BA, van Hylckama Vlieg JE et al (2005a) Identification, cloning, and characterization of a lactococcus lactis branched-chain a-keto acid decarboxylase involved in flavor formation. Appl Environ Microbiol 71(1):303-311

Smit G, Smit BA et al (2005b) Flavour, formation by LAB and biochemical profiling of fermented flavour. FEMS Microbiol Rev 29:591

Song H, Cadwallader KR et al (2008) Odour-active compounds of Jinhua ham. Flav and Frag J 23(1):1-6

Stahnke LH (1999a) Volatiles produced by Staphylococcus xylosus and Staphylococcus carnosus during growth in sausage minces Part I. Collection and identification. LWT Food Sci Technol 32 (6):357-364

Stahnke LH (1999b) Volatiles produced by Staphylococcus xylosus and Staphylococcus carnosus during growth in sausage minces Part II. The influence of growth parameters. LWT Food Sci Technol 32(6):365-371

Steinhaus P, Schieberle P (2007) Characterization of the key aroma compounds in soy sauce using approaches of molecular sensory science. J Agric Food Chem 55(15):6262-6269

Strecker A (1862) On a peculiar oxidation by alloxan (in German). Justus Liebigs Ann Chem 123:363

Swiegers JH, Pretorius IS (2005) Yeast modulation of wine flavor. Adv Appl Microbiol 57:131-175

Swiegers JH, Bartowsky EJ et al (2005) Yeast and bacterial modulation of wine aroma and flavour. Aust J Grape Wine Res 11(2):139-173

Tanous C, Chambellon E et al (2006) Glutamate dehydrogenase activity can be transmitted naturally to Lactococcus lactis strains to stimulate amino acid conversion to aroma compounds. Appl Environ Microbiol 72(2):1402-1409

Temino DM-RD, Hartmeier W et al (2005) Entrapment of the alcohol dehydrogenase from Lactobacillus kefir in polyvinyl alcohol for the synthesis of chiral hydrophobic alcohols in organic solvents. Enzyme Microbial Technol 36(1):3-9

Ter Schure EG, Flikweert MT et al (1998) Pyruvate decarboxylase catalyzes decarboxylation of branched-chain 2- oxo acids but is not essential for fusel alcohol production by Saccharomyces cerevisiae. Appl Environ Microbiol 64(4):1303-1307

Tjener K, Stahnke LH et al (2004a) Addition of a-ketoglutarate enhances formation of volatiles by Staphylococcus carnosus during sausage fermentation. Meat Sci 67(4):711-719

Tjener K, Stahnke LH et al (2004b) The pH-unrelated influence of salt, temperature and manganese on aroma formation by Staphylococcus xylosus and Staphylococcus carnosus in a fermented meat model system. Int J Food Microbiol 97(1):31-42
Tucker JS, Morgan ME (1967) Decarboxylation of a-keto acids by Streptococcus lactis var. maltigenes. Appl Environ Microbiol 15 (4):694-700

Ur-Rehman S, Fox PF (2002) Effect of added $\alpha$-ketoglutaric acid, pyruvic acid or pyridoxal phosphate on proteolyis and quality of cheddar cheese. Food Chemi 76(1):21-26

Van De Guchte M, Kodde J et al (1990) Heterologous gene expression in Lactococcus lactis subsp. lactis: synthesis, secretion, and processing of the Baccilius subtilis neutral protease. Appl Environ Microbiol 56(9):2606-2611

Vanderhaegen B, Delvaux F et al (2007) Aging characteristics of different beer types. Food Chem 103(2):404-412

Van Der Meulen R, Scheirlinck I et al (2007) Population dynamics and metabolite target analysis of lactic acid bacteria during laboratory fermentations of wheat and spelt sourdoughs. Appl Environ Microbiol 73(15):4741-4750

van der Sluis C, Smit BA et al (2000) Regulation of aspartate-derived amino-acid metabolism in Zygosaccharomyces rouxii compared to Saccharomyces cerevisiae. Enzyme Microbial Technol 27(12):151-156

van der Sluis C, Rahardjo YSP et al (2002) Concomitant extracellular accumulation of alpha-keto acids and higher alcohols by Zygosaccharomyces rouxii. J Biosc Bioeng 93(2):117-124

van Hylckama Vlieg JET, Hugenholtz J (2007) Mining natural diversity of lactic acid bacteria for flavour and health benefits. Int Dairy J 17(11):1290-1297

Vesely P, Lusk L et al (2003) Analysis of aldehydes in beer using solidphase microextraction with on-fiber derivatization and gas chromatography/mass spectrometry. J Agric Food Chem 51(24):6941-6944

Vuralhan Z, Luttik MAH et al (2005) Physiological characterization of the ARO10-dependent, broad-substrate- specificity 2-oxo acid decarboxylase activity of Saccharomyces cerevisiae. Appl Environ Microbiol 71(6):3276-3284

Ward DE, Ross RP et al (1999) Catabolism of chranched-chain a-keto acids in Enterococcus faecalis: the bkd gene cluster, enzymes and metabolic route. J Bacteriol 181(17):5433-5442

Whetstine MEC, Drake MA et al (2006) Enhanced nutty flavor formation in cheddar cheese made with a malty Lactococcus lactis adjunct culture. J Dairy Sci 89(9):3277-3284

Williams AG, Noble J et al (2004) The effect of a-ketoglutaric acid on amino acid utilization by nonstarter Lactobacillus spp. isolated from Cheddar cheese. Lett Appl Microbiol 38(4):289-295

Wright J, Wulfert $\mathrm{F}$ et al (2007) Effect of preparation conditions on release of selected volatiles in tea headspace. J Agric Food Chem 55(4):1445-1453

Yep A, Kenyon GL et al (2006) Determinants of substrate specificity in $\mathrm{KdcA}$, a thiamin diphosphate-dependent decarboxylase. Bioorg Chem 34(6):325-336

Yvon M, Rijnen L (2001) Cheese flavour formation by amino acid catabolism. Int Dairy J 11(4-7):185-201

Yvon M, Thirouin S et al (1997) An aminotransferase from Lactococcus lactis initiates conversion of amino acids to cheese flavour compounds. Appl Environ Microbiol 63(2):414-419

Yvon M, Berthelot S et al (1999) Adding alpha-ketoglutarate to semihard cheese curd highly enhances the conversion of amino acids to aroma compounds. Int Dairy J 8(10-11):889-898

Yvon M, Chambellon E et al (2000) Characterization and role of the branched-chain aminotransferase (BcaT) isolated from Lactococcus lactis subsp cremoris NCDO 763. Appl Environ Microbiol 66(2):571-577

Zehentbauer G (2001) Apparatus for the quantitative analysis of the aroma of french bread and its loss during storage. Adv Exp Med Biol 488:175-185 
Zhou Q, Wintersteen CL et al (2002) Identification and quantification of aroma-active components that contribute to the distinct malty flavor of buckwheat honey. J Agric Food Chem 50(7):2016-2021

Zhu K, Bayles DO et al (2005) Precursor and temperature modulation of fatty acid composition and growth of Listeria monocytogenes cold-sensitive mutants with transposon-interrup- ted branched-chain a-keto acid dehydrogenase. Microbiology 151 (2):615-623

Ziegleder G (1991) Composition of flavor extracts of raw and roasted cocoas. Z Lebensm Unters Forsch 192(6):521-525

Zink MW, Sanwal BD (1962) The distribution and substrate specificity of L-leucine dehydrogenase. Arch Biochem Biophys 99:72-77 